\title{
Flusser e a cidade como Gesamtkunstwerk (obra de arte total)
}

\author{
Marcio Seligmann-Silva' \\ I - UNICAMP \\ Campinas (SP), Brasil
}

Resumo: Este trabalho apresenta como a teoria das imagens técnicas culmina, no filósofo Vilém Flusser, em uma teoria da cidade como Gesamtkunstwerk (obra de arte total). Esse conceito, que tem uma origem romântica e ficou conhecido sobretudo por conta da ópera de Wagner, descrita como uma tal obra de arte total, é radicalmente modificado por Flusser, que imagina uma sociedade cibernética na qual todos se transformaram em artistas. A arte voltou a ser técnica, numa sociedade totalmente artificial na qual tudo também é arte e a população de artistas constrói suas obras máximas, que são as próprias cidades.

Palavras-chave: Vilém Flusser; obra de arte total; arte e técnica.

Abstract: Flusser and the city as Gesamtkunstwerk (total artwork). This paper discusses how technical images theory led philosopher Vilém Flusser to a theory of the city as Gesamtkunstwerk (total artwork). This concept, originated in Romanticism, became more familiar through Wagner's operas (that were described as total artworks), and was radically changed by Flusser, who imagined a cybernetic society populated only by artists. Art now became technical again, in a totally artificial society in which everything is also art and the artist population builds its great works, which are the cities.

Keywords: Vilém Flusser; total artwork; art and technique.

A cidade do futuro será a única 'obra de arte':

os artistas estarão empenhados na produção da cidade.

Em tese, todos os cidadãos serão artistas.

A cidade passará a ser a obra de arte de seus cidadãos,

e neste sentido criativo será obra de consenso.

Vilém Flusser 
Walter Benjamin concluiu o seu ensaio sobre $A$ obra de arte na era de sua reprodutibilidade técnica, de 1935, com uma afirmação que se tornou um mote, sobretudo desde sua apropriação pelo movimento estudantil de 1968:

\begin{abstract}
"Fiat ars - pereat mundus", diz o fascismo e espera, como o reconhece Marinetti, da guerra a satisfação artística da percepção sensível alterada pela técnica. É esta claramente a última instância do l'art pour l'art. A humanidade, que em Homero foi um dia objeto de contemplação para os deuses olímpicos, tornou-se objeto de sua própria contemplação. Sua autoalienação atingiu tal grau que se Ihe torna possível vivenciar a sua própria aniquilação como um deleite estético de primeira ordem. Assim configura-se a estetização da política operada pelo fascismo. A ele o comunismo responde com a politização da arte. (2013, p.93-94)
\end{abstract}

Três pontos são importantes aqui, se quisermos pensar na atualidade desse ensaio de Benjamin. Primeiro, a ideia de que o Futurismo via na guerra uma espécie de paroxismo do estético - o que poderia ser associado à observação do músico Kalheinz Stockhausen, que ,cinco dias após o ataque às torres gêmeas de Nova York em 2001 declarou em uma entrevista em Hamburgo que esse ataque foi "the greatest work of art imaginable for the whole cosmos". Nessa declaração cínica confluem teoria do sublime com a ideia de Gesamtkunstwerk.

Outra ideia que importa destacar na passagem de Benjamin é a que propõe uma mudança em nossa percepção sensível do mundo, determinada por mudanças tecnológicas. Ou seja, para o filósofo berlinense haveria uma relação direta entre as tecnologias e mudanças em nosso aparatus corpóreo. Por fim, destaco a ideia da politização da arte como resposta à estetização da política levada a cabo pelo fascismo.

Minha proposta neste texto é mostrar como para Vilém Flusser, esse grande teórico da comunicação e das mídias da segunda metade do século XX, uma vez que para ele vivemos em uma era pós-histórica, não haveria mais essa contradição entre a politização da arte e a estetização da política. Esse ponto é fundamental e de grande importância: Flusser, diferentemente da geração de Benjamin, pensa a política não mais em termos de um triunfo do homo politicus sobre o homo aestheticus, mas o contrário. A arte é a superação da politica: isso é uma reversão do hegelianismo e do marxismo, mas que, paradoxalmente, não abre mão de pensar uma política-estética ou estética-política de modo crítico. Na era pós-histórica, a estetização da política seria determinada pelas novas tecnologias. Flusser desloca a reflexão sobre o Gesamtkunstwerk e o pensa a partir dessa virada pós-histórica, que nos coloca diante da tarefa de criar nosso mundo artisticamente.

Diferentemente do que acontecia na Idade Moderna, que foi marcada pela separação entre técnica e arte, agora a técnica reabsorve a arte e reestabelece "a unidade precedente entre 'ars' e 'techné'. Tal tendência é observável em toda parte: design, arte publicitária, e sobretudo imagens técnicas do tipo fotografia e filme" (FLUSSER, s.d.1). Para Flusser, não podemos mais traçar uma linha divisória entre epistemologia, ética e estética: 
Todo objeto informado por homem (todo objeto cultural) revelará, sob análise, parâmetros epistemológicos, éticos e estéticos intimamente interligados. E que o homem nada conhece sem valorá-lo e vivenciá-lo, nada valoriza sem conhecê-lo e vivenciá-lo, e nada vivencia sem conhecê-lo e valorá-lo. De modo que todo objeto cultural é, sob certo ângulo "obra de arte", sob outro "objeto útil", (ético), e sob mais outro "objeto atestando a determinado conhecimento". E todo homem engajado em fazer cultural, quer se chame homem político ou cientista, é, sob certo ângulo, artista. Até obras tão "feias" como são as cidades industriais, revelarão, sob análise, seu lado artístico, embora frustrado. A arte não permite ser expulsa do fazer quotidiano, sob pena do homem perder a sua humanidade. [...] Neste sentido é pois possível afirmar-se que todo membro da sociedade póshistórica será, quase espontaneamente, artista (FLUSSER, s.d.1).

Esse ser artista do homem pós-histórico é determinado também por Uma nova imaginação (Eine neue Eibildungskraft), título de um pequeno artigo de 1990. Aí ele distingue duas modalidades de imaginação. Uma é aquela capaz de traduzir o mundo em imagens, permitindo que vivamos no mundo: nela se dá um recuou abstrativo no qual o sujeito toma contornos em sua relação com o mundo. Mas essas imagens, como Flusser observou em várias ocasiões, tornam-se elas mesmas obstáculos diante do mundo. A crítica dessas imagens levou, por sua vez, ao domínio da escrita alfabética. No entanto, a nova imaginação que interessa a Flusser e que marcará a virada pós-histórica e a passagem para o triunfo do homo aestheticus é a passagem da escrita alfabética para o cálculo. O código numérico invade o código alfabético e permite a sintetização e não mais apenas a representação (tanto como Repräsentation, ou seja, duplo do mundo, como enquanto Vorstellung, ideia). Essas imagens não significam mais o mundo, mas criam. As imagens computacionais, para Flusser, implicam uma autonomização da imaginação (2007a, p.173). É interessante que, em meio a essa teoria da imaginação técnica, ele toque em um ponto que justamente era central na citada conclusão do ensaio benjaminiano sobre a obra de arte. Se Benjamin criticava Marinetti por sua estetização da política como realização da l'art pour l'art, Flusser reverte essa crítica por meio de sua nova teoria da imaginação:

A própria intencionalidade por trás da nova imaginação é aquilo que a tradição chamava de "estética pura" (l'art pour l'art). Por isso pode-se dizer, então, que o que diferencia a nova imaginação da antiga é o fato de que nela se desdobra a "estética pura" que se encontra instalada na antiga, e de que ela pode fazer isso porque a nova imaginação se encontra num ponto de vista de abstração insuperável, a partir do qual as imagens podem ser criticadas e analisadas. Dito de outro modo: somente quando as imagens são feitas a partir de cálculos, e não mais de circunstâncias [...] é que a "estética pura" (o prazer no jogo com "formas puras") pode se desdobrar; somente assim é que o Homo faber pode se desprender do Homo ludens (2007a, p.175). 
Flusser, como Hannah Arendt já o descrevera em seu ensaio The Human Condition, pensa a sociedade pós-trabalho, na qual as máquinas passam a operar todo o fazer. Resta aos seres humanos a criatividade, ou seja, a

elaboração dos modelos a serem imprimidos automaticamente sobre os objetos. O homem passa a ser "programador da história", e seu fazer passará a ser a manipulação das informações a serem impressas sobre o mundo, o "software". Pela primeira vez, desde que o homem é homem, poderá ele dedicar-se a tarefa negativamente entrópica de preservar informações em memórias, e criar informações novas, isto é: ser plenamente homem (FLUSSER, s.d.1).

Se para esse poderoso historiador e teórico da escrita, após o ápice da cultura escrita no século XIX, o mundo caminha em direção às imagens, a questão é como evitar a estetização fascista do mundo. Os artistas e os teóricos das imagens devem se voltar para construir uma sociedade na qual não devem imperar os valores estabelecidos pelos programadores dos aparelhos. Utilizando a teoria da fotografia como teoria social, Flusser destaca a figura do fotógrafo experimental que tenta desviar do programa da câmera (The Potograph as Post-industrial object, 1986, p. 330). Ele é a prova da inexistência, hoje, da separação entre técnica e arte, sobretudo quando levamos em conta a fotografia digital, já teorizada por Flusser em 1985. E ele vai mais longe, argumentando também do ponto de vista da teoria da ciência:

\begin{abstract}
De modo mais significativo, não existe nenhuma distinção básica entre pesquisa científica e artística: ambas são ficções na busca da verdade (as hipóteses científicas sendo ficções). Imagens eletromagnéticas superam esse divórcio porque elas são o resultado da ciência e estão a serviço da imaginação. Elas são o que Leonardo da Vinci costumava chamar de "fantasia essata". Uma imagem sintética de uma equação fractal é tanto uma obra de arte como um modelo de conhecimento. Portanto, a nova fotografia não apenas supera a classificação tradicional das várias artes (ou seja, pintura, música, literatura, dança e teatro, todos reunidos em unidade), mas ela também supera a distinção entre duas culturas (ou seja, ambas, arte e ciência). Ela torna possível uma obra total com a qual Wagner nunca sonhou (1986, p. 331).
\end{abstract}

Mas esse sonho de uma sociedade de artistas/cientistas criativos capazes de fazer uma Gesamtkunstgesellschaft (sociedade da obra de arte total) não está livre do pesadelo fascista, que assombrava a passagem de Benjamin que citamos acima. Para Flusser, a sociedade das imagens digitais deveria também estar atenta para sua tarefa de lutar contra a sociedade totalitária, na qual imperam os discursos (unidirecionais e monológicos), e visar à construção de uma sociedade dialógica. Em seu ensaio $O$ universo das imagens técnicas, originalmente de 1985, assim como no ensaio The Potograph as Post-industrial object, predomina a visão otimista dessa sociedade informatizada dialógica: 
Cabos e outros canais reversíveis portarão informações em ambos sentidos. A nova fotografia pode ser modificada pelo receptor para ser enviada de volta, portanto modificada, ao emissor. Todo mundo será capaz de colaborar na elaboração da informação (dentro dos limites impostos pela automação). A democracia tornou-se tecnicamente possível pela primeira vez desde a Revolução Industrial. Resumindo: a nova fotografia será diferente da química na medida em que será praticamente eterna, ela tornará possível a arte total e permitirá o funcionamento da democracia (1986, p. 331; eu grifo).

O indivíduo dessa sociedade telemática, ao se ver livre do trabalho, poderá se dedicar ao ócio produtivo. Flusser via no fim do trabalho a libertação e a liberdade para mergulharmos na sociedade dialógica da informação pura.

Isso, evidentemente, é chamado de "jogo" e a revolução cultural atual pode ser vista como uma mutação do "homo faber" no sentido do "homo ludens". Todo assunto sério será relegado ao apparatus e a nova geração irá jogar seus jogos e olhar para trás com desprezo para a seriedade animal das gerações passadas (1985, p. 331).

Esse homo ludens estaria também liberto de sua dependência com relação aos objetos que o condicionam e alienam. Nasceria uma comunidade informacional para além do espaço e do tempo: sem objeto também o tempo deixa de incidir sobre a cultura. A informação imaterial estaria no centro dessa cultura pós-industrial e pós-objetiva e os indivíduos viveriam intensamente uma existência intersubjetiva que se inscreveria em memórias imperecíveis. E Flusser conclui:

Será uma arte total e todo ser humano tornar-se-á, potencialmente, um artista universal. O ser humano não existirá mais como um sujeito em relação a um universo objetivo, mas como um nó dentro de uma rede social que transcende o espaço-tempo. Isso é, evidentemente, utópico. Catástrofes podem evitar isso. Ainda assim, ela se tornou uma utopia tecnicamente factível (1985, p. 331; eu grifo).

Essa teoria da utopia social como Gesamtkustwerkgesellschaft está também clara tanto no referido ensaio $O$ universo das imagens técnicas como nos inúmeros artigos de Flusser nos quais pensa a arte e a cidade. Ou seja, a sua obra destaca uma convergência entre as artes, as técnicas e a cidade. Filosofia política, epistemologia e estética se fundem. Não se trata, portanto, mais do antigo sonho neorromântico do Gesamtkunstwerk, associado ainda a uma ideia de purismo estético e da arte como "torre de marfim", mas sim de uma fusão das faculdades humanas e também das áreas do conhecimento, sob a égide das artes. Para Flusser, "a verdadeira arte é a vanguarda da humanidade: objetiva os sonhos de seu tempo e prepara a modificação da realidade" (FLUSSER, s.d. 2, p.5). Mas vale lembrar que também esse conceito ampliado do Gesamtkustwerk já fora pensado pelos românticos alemães de lena. Friedrich Schlegel, por exemplo, acreditava que o ato transcendental é 
a unificação da ação com o compreender. $\mathrm{O}$ artista seria aquele capaz desse ato. Ele seria o indivíduo transcendental. Novalis definiu a "poesia transcendental" como mistura de poesia com filosofia (1978, p. 325). Para Schlegel vale: "Die Poesie ist die intellektuale Anschauung der Menschheit" ("A poesia e a intuição intelectual da humanidade"; 1963, p. 208); e para Novalis: "Der Künstler ist durchaus transcendental" ("O artista é totalmente transcendental"; 1978, p. 323). A diferença fundamental nesse ponto entre os românticos da virada do século XVIII-XIX e Flusser é, evidentemente, que a Einbildungskraft, entronizada por Schlegel e Novalis (na senda aberta pela terceira Crítica kantiana), não era e nem poderia ser aquela que joga livremente com calculi como veio a acontecer na segunda metade do século XX. Essa imaginação sintetizadora e absolutamente criativa rompe com o modelo de saber iluminista e romântico. Além disso, e como uma decorrência disso, a poesia não era para os românticos a superação, no sentido de uma Aufhebung, da política (ética) e do saber (entendimento), mas simplesmente o aspecto visto como sendo o mais nobre do real. Assim, Novalis escreveu: "Es ist nur nicht reine Poesie, wenn die Einbildungskraft um des Verstandes, des Erkenntnissvermögens willen, erregt wird". ("Não se trata de poesia pura, quando a imaginação é excitada em função do entendimento, da faculdade de conhecer." 1978, p. 357). Em suas preleções de história da filosofia ministradas em Colônia, Friedrich Schlegel deixa clara essa hierarquia e divisão de trabalho entre, por um lado, a ciência e a filosofia (com seu saber analítico, sistemático e conceitual) e, por outro, as artes, coisa que justamente estaria superada para Flusser. Schlegel formula: "In der Poesie ist das Höchste nur angedeutet, sie läßt es nur ahnen, statt es wie die Philosophie in bestimmte Formeln zu bringen und erklären zu wollen." ("Na poesia o mais elevado só pode ser indicado, ela permite apenas sugeri-lo, ao invés de querer explicar colocando em certas fórmulas como se dá na Filosofia". 1964a, p.166).

Flusser introduz nessa filosofia romântica questões derivadas da revolução midiática. É como se apenas agora, na era telemática e das imagens digitais, essa plasticidade da cultura pudesse efetivamente se concretizar. Mas se no programa romântico não existia um alarme contra o fascismo, em pleno século XX, Flusser, um filósofo que perdeu seu pai em Buchenwald e sua mãe e irmã em Auschwitz, não poderia deixar de levar em conta o potencial fascista desse pensamento do mundo estetizado. Assim, se para Novalis era poético afirmar, por exemplo, "Poësie ist die große Kunst der Construction der transcendentalen Gesundheit. Der Poët ist also der transcendentale Arzt" ("Poesia é a grande arte de construção da saúde transcendental. O poeta é portanto o médico transcendental" 1978, p. 324), para Flusser ideias desse tipo poderiam muito bem lembrar a ideologia da higiene genocida, do tipo que imperou no nazismo. Temos aqui, portanto, um terceiro motivo porque a relação do pensamento de Flusser com o romantismo alemão deve ser visto cum grano salis.

Assim, no ensaio $O$ universo das imagens técnicas, ele indica a coexistência de dois tipos de imagens técnicas: uma aponta em direção às sociedades totalitárias. 
Nelas, as pessoas são reduzidas à categoria de funcionários das imagens. A outra aponta para a sociedade "telemática dialogante dos criadores de imagens e dos colecionadores de imagens" (2008, p. 14). A primeira utopia tem tons negativos, a segunda, positivos, observa Flusser. Essas imagens técnicas são marcadas também por uma espécie de retorno ao concreto, uma vez que as imagens tradicionais se davam sob a batuta da razão e da abstração. Para Flusser, "apenas a imagem é o concreto" (2008, p. 137). Se para Freud os sonhos são uma porta para nosso mais profundo real, Flusser preconiza uma sociedade telemática na qual "os sonhos serão o concreto" (2008, p. 139). Também podemos lembrar do Benjamin do referido artigo sobre a obra de arte, para quem também são as imagens técnicas que penetram o real, ao invés de manter distância dele. ${ }^{1}$

É como se para Benjamin e Flusser a realidade se tornasse uma série de pedras de lego que podem ser reconstruídas ad libitum. Flusser escreve: "A sociedade utópica telemática torna-se a rede na qual a vertigem da queda se transforma em vertigem da aventura. Os participantes dessa sociedade apertarão teclas como as apertam atualmente os escritores, os pianistas, os 'imaginadores'". (2008, p. 97s). Trata-se de conquistarmos os gadgets e "submetê-los à nossa liberdade", ao invés de nos submeter a eles. A futura sociedade será deliberadamente "artificial: obra de arte. Nada haverá nela de 'orgânico', de 'natural', de 'espontâneo'." (2008, p. 98). Ela será pura superficialidade e suas regras serão lúdicas, regras de jogo. A vida será arte nesse sentido lúdico: "um fazer limitado por regras que são modificadas pelo fazer mesmo" (2008, p. 98), como nos juízos reflexionantes de Kant. Cada um se torna jogador de um jogo no qual todos são vencedores: "a cada lance o universo do jogo fica enriquecido" (2008, p. 149).

O último capítulo do ensaio $O$ universo das imagens técnicas nos leva ao coração da visão onírico-utópica de Flusser de nosso futuro-presente cibernético. Ele utiliza a metáfora da música de câmara para descrever esse mundo no qual somos vistos como formigas em um gigantesco formigueiro, cada qual com seu teclado ligado a sistema em rede ordenado ciberneticamente. Cada qual fazendo suas imagens, mas todas podendo ser recebidas por todos. No mundo pós-histórico cibernético sonhado por Flusser nesse ensaio, ciberneticamente, não haveria mais autoridade, mas antes se construiria uma sociedade cérebro, uma infindável caixa preta. Nossos netos (na verdade, agora, nossos filhos) seriam seres que viveriam atados a terminais, as suas necessidades biológicas seriam solucionadas mecanicamente, inclusive as de reprodução. Seres incorpóreos populariam esse gigantesco formigueiro cibernético. Esses cérebros descarnados teriam uma organização pós-ética e pós-política, assim como não caberia mais se falar em hermenêutica ou significação. Trata-se do triunfo da estética sobre todos os demais níveis

1 Cito as palavras de Benjamin: "Mago e cirurgião relacionam-se como pintor e operador de câmera. Em seu trabalho, o pintor observa uma distância natural em relação ao dado; o operador de câmera, ao contrário, penetra profundamente no tecido daquilo que está dado. As imagens que ambos geram a partir daí são tremendamente diferentes. A do pintor é total, a do operador de câmera é dividida em múltiplas partes que se reúnem segundo uma nova lei". (2013, p. 81) 
da cultura e da natureza. O tempo achatado, no entanto, é um presente que garante um tipo de eternidade que tende ao tempo místico do agora: "As imagens aparecem como relâmpago e como relâmpago desaparecem. No entanto, são 'eternas', porque guardadas em memórias, e também recuperáveis 'imediatamente'. Logo, não há mais 'o' espaço: todos estamos aqui juntos, não importa onde estejamos. Logo, não há mais 'o' tempo: tudo está comigo agora, não importa quando tenha acontecido". (2008, p. 149). A história é superada em um alef cibernético que apresenta a espaço-temporalidade concentrada de modo rizomático e concentrado. Nesse super-cérebro estetizado as pessoas serão "formigas curiosas: secretarão arte em vez de ácido fórmico [...] e sobretudo viverão em orgasmo cerebral permanente". E Flusser arremata, para nosso espanto: "Se isto for formigueiro, aceito o modelo" (2008, p. 127-31).

Aqui o modelo da música de câmara é tomado em oposição ao sinfônico: nele predomina a improvisação, não existe um regente, não há um público (a teoria), cada um faz sua música como se fosse um solo e, por fim, como em toda música, não há mais representação no sentido de cópia. "Imagens técnicas são 'arte pura', no sentido em que apenas a música é arte pura" (2008, p. 146). Ou seja, como na tradição do Gesamtkustwerk, vemos aqui também essa ideia paradoxal de uma arte total que ao mesmo tempo é "arte pura" e convergência de todas as mídia. Pois para Flusser está claro que "música e imagem se juntam, que nelas [nas tecno-imagens] música se torna imagem, imagem se torna música, e ambas se superam mutuamente. [...] Na imagem técnica não se trata de intermix, mas de mútua superação de música e de imagem” (2008, p. 146). Essas imagens são música imaginativa, sonhos enquanto devaneios diurnos que se traduzem em imagens, em suma, "criatividade concreta" (2008, p. 150). Também para os românticos, vale retomar o paralelo, a música foi entronizada como rainha das artes, justamente por ser a mais distante do elemento imitativo, a arte mais livre. Por outro lado, a música como modelo das artes nunca chegou a se tornar um modelo da sociedade como um todo, nem mesmo uma metáfora de todo o saber e do mundo, como é proposto por Flusser. Assim, Schlegel escreveu no mesmo curso de filosofia acima mencionado:

Também a linguagem mais elevada deve ser música; aqui a poesia é o mediador que conecta a música com a linguagem. - A música nunca pode se aproximar tanto da clareza da linguagem, quanto a linguagem pode ser musical na poesia; no entanto, a linguagem nunca será tão profunda e capaz de tocar imediatamente nossa consciência, tão clara para o sentimento, como a música. - A verdadeira música nunca pode apresentar outra coisa que não a infinita unidade e plenitude; aqui cresce toda a consciência plena do ser humano. Na poesia tornada música isso até é possível; no entanto em um grau muito mais fraco e incompleto (1964b, p. 58).

Para Schlegel, existe uma espécie de divisão de trabalho entre a música, a poesia e a filosofia. A música, como na ópera wagneriana, pode ser indicação do todo e do infinito, 
fusão daquilo que a força alienante da modernidade dissolveu e separou, um substituto da religião como religatio, mas não sintetização do mundo. Para Flusser, ocorre de modo muito mais radical uma vertiginosa tradução do concreto em termos musicais. Não se trata só de uma diferença de grau, ela se tornou qualitativa.

Essa construção da ideia de uma criatividade concreta em uma sociedade de artistas também pode ser acompanhada nos textos de Flusser especificamente voltados para as artes. Ele faz um elogio do trabalho artístico como obra que tende ao coletivo (dialógico), como lemos em seu texto sobre a $18^{a}$ Bienal de São Paulo de 1985. A curadoria é pensada como a construção de um Gesamtkunstwerk, ainda que Flusser não empregue esse termo. "A estrutura tradicionalmente discursiva (o artista fala, o receptor escuta) cede lugar à estrutura dialógica (os artistas falam entre si para darem palavra final ao visitante). Criar tal espaço-tempo dialógico é o problema de toda criatividade futura" (FLUSSER, s.d.3, p. 4). Já em seu artigo "Arte viva" (1988), Flusser vai fazer uma defesa da união dos artistas com os geneticistas: na biotécnica o artista pode efetivamente auxiliar no novo design da vida. Novamente, arte e técnica se unem para pensar na vida como obra de arte total.

A emancipação do caráter de objeto da arte, na visão de Flusser, a direciona no sentido da plasmação da vida e de seu meio: a cidade. Assim, ele pôde afirmar que "é a rua, e não a galeria, que distribui a arte atual, e a distribui fazendo participar o receptor, não relegando ele a papel passivo, como o faz a galeria" (FLUSSER, s.d. 5, p. 3). O novo artista deve recodificar as mensagens da arte de elite e levá-las aos canais das massas, "portanto abandonar livros, exibições e concertos, e penetrar a TV, a produção industrial estereotipada e as ruas" (FLUSSER, s.d.6, p. 9). O artista deve penetrar os modelos programados. Tornar-se programador. Desconstruir os modelos fascistas. Assim, é tão legítimo ele levar suas obras às ruas, como encarar suas obras e sua atuação como designer, em programas políticos ou mesmo no planejamento econômico (FLUSSER, s.d.5, p. 4). É na quarta de suas aulas no curso "Explicar a arte", que ministrou na Galeria Paulo Figueiredo, dedicado ao tema "Explicar o efeito político-social", que seu ponto de vista sobre o papel revolucionário da arte fica mais claro. Se a primeira Revolução Industrial havia mantido a divisão entre o público e o privado, a segunda revolução, telemática, explode essa estrutura, já pelo simples fato de "reformular a estrutura da cidade" (FLUSSER, s.d.7, p. 1). "A cidade pós-indústrial, a cidade de fios (wired city), vai abolir a oscilação entre o espaço público e o privado. Vai instalar [a] rede comunicativa" (FLUSSER, s.d.7, p. 1). Quando portas e janelas são substituídas por fios, é a própria consciência humana que está sendo transformada. Hegel deduzira da diferença entre o espaço privado e o público a consciência infeliz. Esse é um Leitmotiv na filosofia de Flusser que recorda disso para mostrar o fim dessa situação, pois esse espaço urbano/político de que Hegel partia foi radicalmente modificado. Se a modernidade lança seus habitantes no nomadismo (FLUSSER, 2011, p. 89) e na ruptura com suas origens (gerando a Bodenlosigkeit, ausência de chão e de fundamento), ela produz também uma libertação da pátria: a Heimatlosigkeit 
(2007b, p. 223), ou seja, um feliz esquecimento da pátria, do lar, da origem, que nos amarrava de modo cego a mandamentos e preconceitos. A moradia que abandona o imóvel e se torna dinâmica já pode ser percebida nas mudanças de nossas casas: Flusser observa que as nossas paredes estão sendo vazadas por cabos que conectam o mundo em redes. Essa revolução informacional também abole a condição existencial que gerava a consciência triste. Não existe mais o interior das casas se opondo ao seu exterior. Agora o software vale mais do que o hardware. Esse sujeito da cidade telemática pode superar essa doença da alma. Enquanto artista, doravante ele "deverá imprimir seus modelos sobre os programas dos aparelhos. A sua matéria prima não mais será o mundo objetivo, mas a cidade" (FLUSSER, s.d.7, p. 3). Mas na medida em que o esquema que ordenava a política clássica era a divisão entre o espaço público e o privado, agora não tem mais sentido se falar em engajamento político. Na verdade, "a arte passará a substituir-se à política, a qual não terá mais sentido em situação cibernetizada. O artista será o programador da cidade" (FLUSSER, s.d.7, p. 3). Os centros programadores serão alimentados pelos artistas, de modo que "a cidade do futuro será a única 'obra de arte': os artistas estarão empenhados na produção da cidade. Em tese, todos os cidadãos serão artistas. A cidade passará a ser a obra de arte de seus cidadãos, e neste sentido criativo será obra de consenso" (FLUSSER, s.d.7, p. 4). Flusser está consciente de que esse seu modelo é ambíguo e permite tanto pensar na cidade terrível de automação total e dominada pelos funcionários (reproduzida pela ficção científica ao menos desde "Metrópolis", de Fritz Lang, 1926) como também pode ser a realização do mote da "I'imagination au pouvoir". Se não há mais espaço público para a troca de informações, nem esfera privada para se criar as obras, só resta aos artistas serem os agentes da "única política possível" (FLUSSER, s.d.7, p. 4). Andamos, portanto, na corda bamba entre a "pseudo-arte do Kitsch programado" que leva a cidade a uma entropia final, e a "bela cidade', a cidade na qual viver poderá significar opor a criatividade humana ao absurdo do mundo". "O futuro da cidade", diz Flusser, "está na mão da arte" (FLUSSER, s.d.7, p. 4)

Assim, não surpreende que em seu texto Vom Virtuellen (1991), Flusser tenha se referido explicitamente ao mundo como Gesamtkunstwerk. Contra o senso comum, ele argumenta que aquilo que denominamos de efetividade (wirklich) não é nada mais do que a extrapolação do virtual: "Na vida nós lidamos com o virtual e o efetivo não é mais que uma quimera do pensamento abstrato" (FLUSSER, s.d.8, p. 3). Nesse sentido, perceber é "o computar do virtual" (FLUSSER, s.d.8, p. 3). Daí a pensar o mundo como virtualidade é um passo: "pode-se, então, falar do mundo concreto no qual vivemos que ele é um Gesamtkunstwerk, que os nossos sentidos e o nosso sistema central computam a partir do virtual" (FLUSSER, s.d.8, p. 4). E se o mundo é computação do virtual, em uma palavra, é tradução, isso significa que esse mundo concreto como virtualidade é eminentemente aperfeiçoável. E mais: isso significa também que esse virtual permite inúmeras outras traduções, ou seja, concretizações, que podem ser igualmente ou mais 
concretas do que o nosso sistema central e perceptivo permite. Quando falamos hoje de "virtual" indicamos essas outras possibilidades de Gesamtkunstwerke que os novos sistemas cibernéticos permitem aflorar.

Assim como para o Benjamin citado na abertura deste texto, também para Flusser o concreto parece estar mais próximo de nós por meio das novas técnicas. Benjamin escreveu poeticamente: "O aspecto livre de aparatos da realidade tornou-se aqui [no estúdio cinematográfico] o mais artificial, e a visão da efetividade imediata tornou-se a flor azul no país da técnica" (2013, p. 80). Benjamin também falava nesse ensaio de 1935 de uma segunda técnica, redentora e não destruidora de nossas naturezas interna e externa, que ele associou à conquista de um novo Spielraum, espaço de jogo, campo de liberdade. Com Flusser, essa conquista deixou de ser tarefa exclusiva do artista e passou às mãos de todos nós, transformados em artesãos de nosso destino.

Marcio Seligmann-Silva é professor titular de Teoria Literária na UNICAMP. É doutor pela Universidade Livre de Berlim e pós-doutor por Yale. Foi professor visitante em Universidades no Brasil, Argentina, Alemanha e México.

m.seligmann@uol.com.br

\section{Referências}

BENJAMIN, W. A obra de arte na era de sua reprodutibilidade técnica. Organização e apresentação M. Seligmann-Silva; trad. Gabriel Valladão Silva, Porto Alegre, L\&PM, 2013.

FLUSSER, V. O universo das imagens técnicas. Elogio da superficialidade. São Paulo: Annablume, 2008. Naify, 2007a.

O mundo codificado: por uma filosofia do design e da comunicação. São Paulo: Cosac

Bodenlos: Uma autobiografia filosófica. São Paulo: Anna Blume, 2007b.

Pós-história. São Paulo: Annablume, 2011.

. Arte na pós-história. Disponível em: http://www.flusserbrasil.com/art121.pdf . Acessado em 12/05/2016. S.d.1

. The Photograph as Post-industrial object. In: Leonardo, 19, 4:329-332. 1986.

Aspectos e prospectos da arte cibernética. Disponível em: http://www.flusserbrasil.com/ art139.pdf . Acessado em 12/05/2016. S.d.2

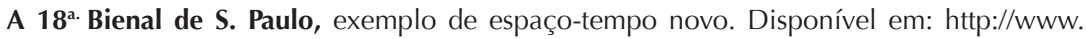
flusserbrasil.com/art62.pdf . Acessado em 12/05/2016. S.d. 3

. Arte viva. Disponível em: http://www.flusserbrasil.com/art138.pdf. Acessado em 12/05/2016. S.d.4

. Como explicar a arte. Explicar a distribuição. Disponível em: http://www.flusserbrasil.com/ art218.pdf . Acessado em: 12/05/2016. S.d.5 
O papel da arte na ruptura cultural. Disponível em: http://www.flusserbrasil.com/art435. pdf . Acessado em: 12/05/2016. S.d.6

Explicar a arte. Explicar o efeito político-social. Disponível em: http://www.flusserbrasil. com/art220.pdf . Acessado em: 12/05/2016. S.d.7

Vom Virtuellen. Disponível em: http://www.flusserbrasil.com/artg431.pdf. Acessado em: 12/05/2016. S.d.8

GULDIN, R. On the Notion of Code Convergence in Vilém Flusser's Work. In: xCoAx 2013, 1st Conference on Computation, Communication, Aesthetics and X, 27th-28th June 2013, University of Bergamo (Italy). Disponível em: http://2013.xcoax.org/pdf/xcoax2013-guldin.pdf .

NOVALIS. Werke, Tagebücher und Briefe. MÄHL, H.-J. ; SAMUEL, R. (orgs.) München: Hanser, vol.2, 1978.

SCHLEGEL, F. Kritische Friedrich-Schlegel-Ausgabe. BEHLER, E. München/ Paderborn/ Wien: Verlag Ferdinand Schöningh, vol. XVIII, 1963.

Kritische Friedrich-Schlegel-Ausgabe. BEHLER, E. München/ Paderborn/ Wien: Verlag Ferdinand Schöningh, vol. XII, 1964a.

Kritische Friedrich-Schlegel-Ausgabe. BEHLER, E. München/ Paderborn/ Wien: Verlag Ferdinand Schöningh, vol. XIII, 1964b. 